\title{
PRÁTICAS CORPORAIS NA EXPERIÊNCIA QUILOMBOLA: UM ESTUDO COM COMUNIDADES DO ESTADO DE GOIÁS/BRASIL
}

\author{
Ana Márcia Silva \\ Universidade Federal de Goiás, Goiânia, Goiás, Brasil \\ José Luiz Cirqueira Falcão \\ Universidade Federal de Goiás, Goiânia, Goiás, Brasil
}

\begin{abstract}
Resumo:
O objetivo deste trabalho é analisar as práticas corporais na experiência quilombola indicando alguns dados de pesquisa realizada com cinco comunidades (Almeida, Cedro, Kalunga, Magalhães e Jardim Cascata) no Estado de Goiás, região central do Brasil, apontando, também, alguns elementos do processo histórico e da agenda política nacional sobre o tema. As folias, danças como o forró, a catira e a sussa, a capoeira, jogos e brincadeiras, além do futebol, são algumas das mais frequentes práticas corporais encontradas, quase todas marcadas por um hibridismo com a cultura de massa e atuando como vetores de reconstrução da tradição em busca da reafirmação da identidade cultural.
\end{abstract}

Palavras-chave: Práticas Corporais. Culturas Tradicionais. Quilombolas.

\section{Introdução}

$A_{\text {o relatar um pouco das práticas corporais observadas, buscamos }}$ as como constituintes dessa condição humana geográfica e historicamente datada, mas também imersa na contemporaneidade. O que observamos nas manifestações culturais dessa parcela da população brasileira é que, obviamente, não se desenvolvem isoladas do contexto contemporâneo, mas também não são determinadas integralmente por ele, mostrando uma interessante tensão que merece ser mais bem investigada.

Destacamos, aqui, duas características comuns da organização territorial quilombola no Brasil, de acordo com dos Anjos (2005): a) distribuição esparsa das construções no território e b) ocupação de regiões de topografia acidentada, na encosta de serras, vales e beiras de rio. Essas são características de boa parte dos territórios quilombo- 
las e determinam seu modo de ser e suas práticas corporais, marcando sua experiência histórica ontem e hoje, com certa dose de isolamento geográfico, assim como político.

Levar em consideração tais elementos implica compreender esses sujeitos em suas relações sociais e ambientais, o que garante certa objetividade ao analisar os usos e o papel das práticas corporais em seu modo de ser quilombola. Esta palavra, inclusive, até há pouco tempo desconhecida para eles bem como para grande parcela da sociedade civil brasileira, constitui atualmente parte importante de sua autopercepção, textualmente identificada numa das entrevistas realizadas na pesquisa: "[...] há um tempo a gente não tinha esse nome e agora eu acho que esse nome faz a gente" (M. M. 51 anos, feminino, entrevista com os adultos, Com. Magalhães, 12/10/2009).

É importante destacar, também, que o poder público não tem conseguido atender minimamente às reivindicações dos quilombolas, nem tampouco cumprir as determinações legais, especialmente a certificação e a titulação das terras que lhes são de direito. Aspectos decisivos para a própria existência dessas comunidades e para a autorreconstrução de sua cultura.

Em Goiás, as comunidades quilombolas certificadas pela Fundação Palmares totalizam 22, já o mapeamento apresentado a seguir mostra 27 ocorrências registradas no ano de 2005. Sabe-se, todavia, que passam de cinquenta (BRASIL, 2003. DOS ANJOS, 2005).

A nossa investigação, realizada entre 2009 e 2011, teve como lócus as seguintes comunidades: 1) Jardim Cascata, situada na cidade de Aparecida de Goiânia; 2) Almeida, a primeira no Estado de Goiás a ser reconhecida, situada no município de Silvânia; 3) Cedro, no município de Mineiros; 4) Magalhães, no município de Nova Roma; e 5) Kalunga, no município de Teresina de Goiás. 


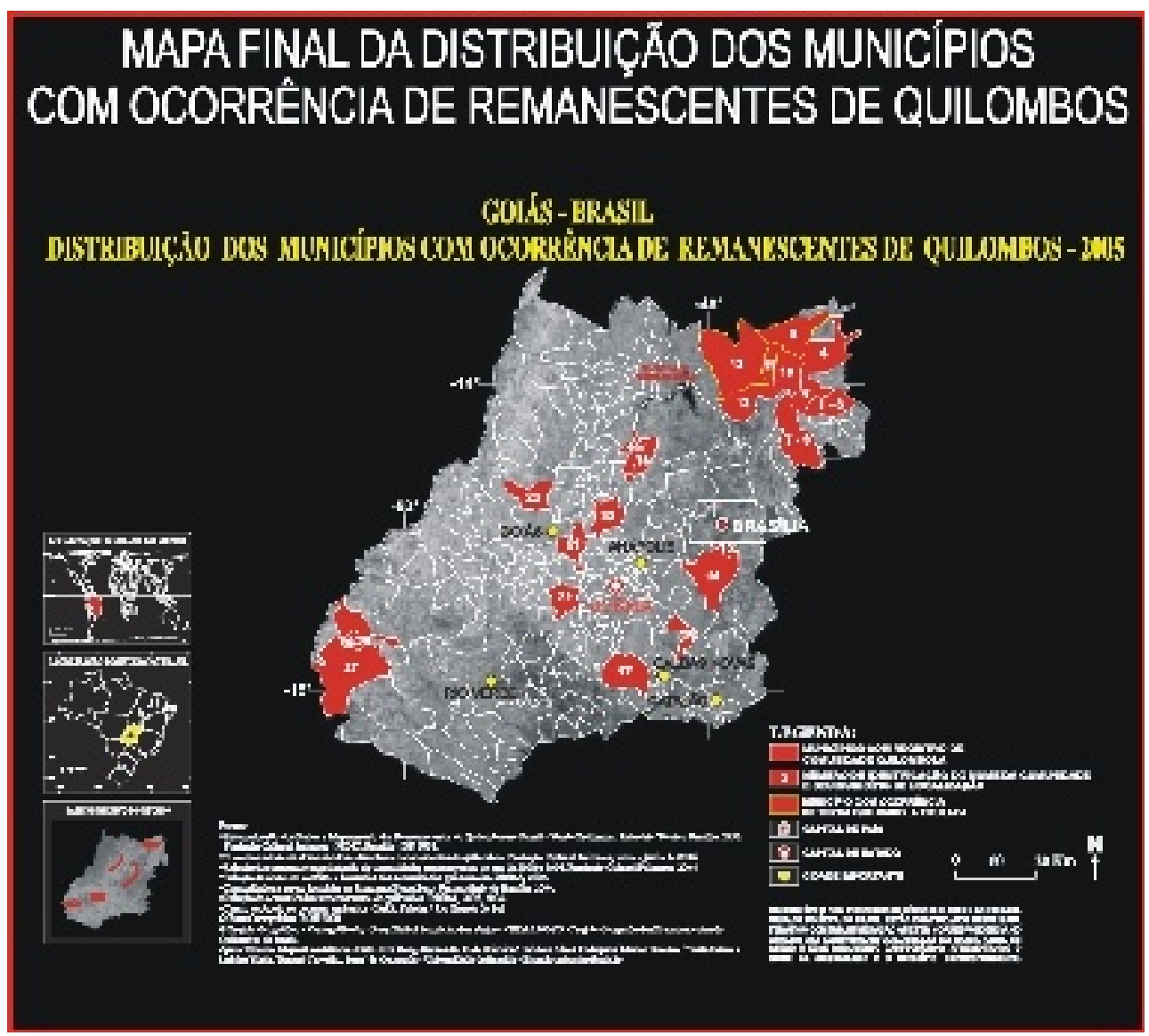

Figura 1: Mapa de Localização das Comunidades Quilombola em Goiás (Fonte: DOS ANJOS, 2005).

De acordo com o Mapa Preliminar dos Remanescentes de Quilombos do Brasil elaborado em 1997¹, 848 ocorrências foram relatadas no Brasil naquele momento. Os dados da Fundação Cultural Palmares mostram 1.820 comunidades certificadas até o ano de 2012. Por força da intensificação da luta empreendida no período de redemocratização do Brasil por segmentos organizados, como tem sido o caso do Movimento Negro, entre outros, os integrantes dessas comunidades passaram da condição de "quase folclóricos" para ativistas incômodos, localizados, no mapa político nacional, em algum lugar entre os trabalhadores sem-terra, os indígenas, as favelas e os universitários cotistas (ARRUTI, 2009).

É pela experiência de ser quilombola, de pertencer a uma comunidade considerada legal e sociologicamente como remanescente de qui-

1-Atividade também coordenada por Rafael Sanzio dos Anjos, atendendo a solicitação oficial da Fundação Cultural Palmares, vinculada ao Ministério da Cultura. 
lombo, juntamente com algum nível de autoconsciência desse fato histórico por parte de seus membros, que buscamos analisar os usos e apropriações das práticas corporais desses grupos. A fala de um integrante de uma das comunidades é expressiva sobre o tema:

Porque algum tempo aqui se você falasse 'fulano é kalungueiro' dava-se mais valor pra um caju do que pra um "kalungueiro" [...] Kalungueiro aqui não tinha valor não. Hoje, depois da lei, muitos que não são, já querem ser porque foi reconhecido e está tendo valor... (J. M. 68 anos, masculino, Com. Magalhães, $12 / 10 / 2010)$

A experiência, aqui, é compreendida no sentido proposto por Edward Palmer Thompson (1981, p. 111), como um conceito polifuncional que remete às culturas específicas, marcadas por condições étnicas e de classe, as quais constituem "homens e mulheres, em sua vida material, em suas relações determinadas, em sua experiência dessas relações e em sua autoconsciência dessa experiência”. É nosso intento analisar em que medida as práticas corporais constituem parte significativa dos modos e costumes com os quais essas corporalidades se expressam. Em outras palavras, temos como propósito observar esse âmbito da experiência na relação com as demais dimensões e com a natureza, considerando-o, portanto, uma experiência étnica, social, geográfica e historicamente construída. Ou seja, buscamos verificar como a identidade quilombola mostra-se nessas corporalidade, sem, assumi-la como um dado a priori.

As práticas corporais são compreendidas, aqui, para além de "técnicas corporais", conforme conceito desenvolvido por Marcel Mauss (1974). Podem ser mais bem compreendidas como conjuntos dessas técnicas com sentidos e significados coletivos e historicamente construídos, característicos das manifestações culturais capazes de englobar as relações de poder, a linguagem e o trabalho. São brincadeiras, jogos, danças, esportes, manifestações culturais, todos portadores de incontáveis técnicas em sua gestualidade característica, nos movimentos de braços, pernas, quadris, cabeça, no encontro com a música, com a bola, com o rio, com o outro. Só compreendemos mais amplamente o sentido e significado dessas gestualidades, assim como sua permanência ou reconstrução, quando observamos mais integralmente cada 
prática corporal, constituída ou mobilizada por seres concretos: não apenas o futebol, mas este futebol, ou este forró, sussa ${ }^{2}$, capoeira...

A experiência quilombola no Brasil, em especial nessa região, marcada pelo bioma do Cerrado e pelas sucessivas descobertas de ouro e pedras preciosas em séculos anteriores, nos faz reconhecer a importância de conhecer algo de sua trajetória de organização e resistência, sua dinâmica histórica, hábitos e relações sociais. Conhecer o que há de remanescência de modos de vida, especialmente, considerando-se os séculos de escravidão no país ${ }^{3}$, tanto em sua duração, em número de escravos e de quilombos, quanto em seus aspectos de hibridismo, um processo de reconstrução político-cultural de grande vitalidade.

\section{Alguns elementos do processo histórico dos Quilombos na região}

De acordo com Dos Anjos (2005), o sistema escravista, ao longo desses quase quatro séculos, resulta de diferentes origens no continente africano e variados destinos fora da África, sendo que os maiores fluxos mantiveram-se em regiões geográficas de interesse europeu. No século XVI, os povos africanos das regiões Alta e Baixa Guiné (atual Serra Leoa, Senegal, Guiné-Bissau e Gâmbia) foram trazidos para as regiões açucareiras de Pernambuco, Bahia, Maranhão e Grão-Pará. No século XVII o tráfego foi dinamizado na Costa de Angola (atualmente Angola, Gabão e Guiné Equatorial) e direcionado para Bahia, Pernambuco, Alagoas, Rio de Janeiro, São Paulo e Centro-Sul do País, alguns movimentos para as províncias do Grão-Pará, Maranhão e atual Rio Grande do Norte. Nos séculos XVII e XVIII ocorreu um maior fluxo de tráfego de escravos para o Brasil, sobretudo provenientes das chamadas Costas de Mina (atualmente, Costa do Marfim, Gana, Togo, Benin, Nigéria e Camarões) e Angola. No século XIX, até a abolição

2-Na literatura acadêmica sobre o tema encontram-se variações na grafia dessa dança popular. Antonio Rodrigues Silva Júnior (2008b, p. 5) informa que "há uma variação linguística para o termo: Sussa, Suça, Sússia. Admite-se que tenham advindo do termo português "Súcia", regressão da palavra "suciedade" (de caráter burlesco). Como regionalismo pode ser compreendido como pagode, reunião familiar, festa familiar".

3-A experiência da escravidão no Brasil, comparada em níveis mundiais ao Holocausto, foi devastadora, mas a resistência a ela foi, em muitos casos, obstinada, materializada por meio de fugas, suicídios, levantes, assassinatos, rebeliões etc.

Pensar a Prática, Goiânia, v. 15, n. 1, p. 1-271, jan./mar. 2012 
do tráfego negreiro no Brasil, os escravos eram trazidos de Gana, Togo, Benin, Nigéria, Gabão, Congo, Angola, Moçambique e Madagascar.

Os registros históricos apontam que, no sertão goiano, na então capitania de Goyaz, os quilombos começaram a se formar em meados de 1727, como afirma Mary Karasch (1996). Região de abundantes riquezas naturais, atravessada por extensos, pitorescos e caudalosos rios (Araguaia, Paranã, Tocantins e Paranaíba), atraiu, desde o século XVIII, grande quantidade de fazendeiros, mineradores e donos de engenhos, o que acabou por reforçar em parte o processo de ensimesmamento português, virando as costas para o litoral e distanciando-se da corte. Para a execução do trabalho forçado, esses exploradores trouxeram milhares de negros comprados nos mercados e entrepostos de venda de escravos. No século XVIII, nas cidades mineradoras de Goiás, os negros chegavam a compor mais de $70 \%$ da população. O desgastante trabalho escravo, a má alimentação, os bárbaros castigos, os maus-tratos e as punições que recebiam dos seus proprietários, fizeram com que muitos negros se revoltassem e fugissem das senzalas e dos engenhos para embrenharem-se nas matas e formarem diversos quilombos, tal como já vinha acontecendo há algum tempo em outras regiões do país (SILVA, 2008).

Nesses lugares ermos os negros encontravam "florestas densas, montanhas inexploradas, cerrados espinhosos, manguezais infestados de mosquitos, ilhas escondidas, inúmeros rios e muita distância dos brancos - tinham, enfim, locais onde levantar quilombos e viver em liberdade" (KARASCH, 1996, p. 245). Diferentemente dos imigrantes europeus que aportaram no Brasil novecentista e tratavam a natureza como adversária áspera e feroz, que deveria ser explorada e vencida (MEYER, 2000; BRANCHER e AREND, 2001; SILVA, PERINI e AGUSTINI, 2003), os negros quilombolas de Goiás, pareciam apresentar uma percepção da natureza como parceira, provedora e aliada, como desenvolvemos melhor em outro texto ${ }^{4}$. Lócus privilegiado para esconder-se, buscar abrigo e retirar alimento, ainda que com o enfrentamento de adversidades climáticas e dificuldades materiais.

4-Sobre a relação dos quilombolas com a natureza, conferir Silva (2011); Salles da Silva (2011); Tucunduva (2011) In: SILVA, A. M.; FALCÃO, J. L. C. (orgs.) Práticas corporais em comunidades quilombola de Goiás. Goiânia, Editora PUC/GO, 2011.

Pensar a Prática, Goiânia, v. 15, n. 1, p. 1-271, jan./mar. 2012 
Longe dos centros administrativos, essas pessoas empenhavam-se em subsistir no meio da mata e, em muitos casos, dedicavam-se à extração de minérios para a compra de sua alforria. Alguns saques eram efetuados em comitivas e em propriedades, o que provocava, por vezes, as investidas contra os quilombos, batalhas essas marcadas por grupos de negros dizimados. Conflitos entre índios e quilombolas também eram corriqueiros, com frequentes casos de roubos de crianças e jovens mulheres entre uns e outros, talvez, para constituir novos casais e gerar mais filhos, ampliando suas chances de autorreprodução. As fontes que se referem a esse período e a esses confrontos com outros grupos tradicionais são, na grande maioria, orais.

As histórias de resistência, migrações, fugas e roubos possibilitam um esforço para o entendimento da dinâmica desses grupos e apareceram com certa frequência nas entrevistas da pesquisa realizada com membros mais antigos, sobretudo nas comunidades mais tradicionais ou distantes dos meios urbanos, como é o caso dos Kalunga, dos Magalhães e do Cedro.

\section{Das práticas corporais em comunidades quilombolas}

Vinte de janeiro! É dia de festa para os Magalhães... Em honra a São Sebastião, como promessa desde há décadas, a festividade é organizada pelo filho mais velho da matriarca dessa comunidade, situada às margens do rio Paranã, município de Nova Roma, no nordeste de Goiás. Na chegada à comunidade já se observa que a ocasião é especial, pois há mais pessoas do que os moradores usuais. Os sons e movimentos nos levam a um descampado em meio aos arbustos. Um jogo de futebol se desenrola naquele espaço com traves feitas de estacas extraídas da mata e sem qualquer marcação de linhas ou limites, para além daqueles criados pela própria vegetação. Os jogadores, jovens rapazes entre quinze de vinte e cinco anos, diferenciam-se entre os times com e sem camiseta; não se identifica a presença de qualquer tipo de juiz ou arbitragem. O jogo corre animado e sem brigas, ainda que com alguns desentendimentos esporádicos sobre posse de bola ou falta. 


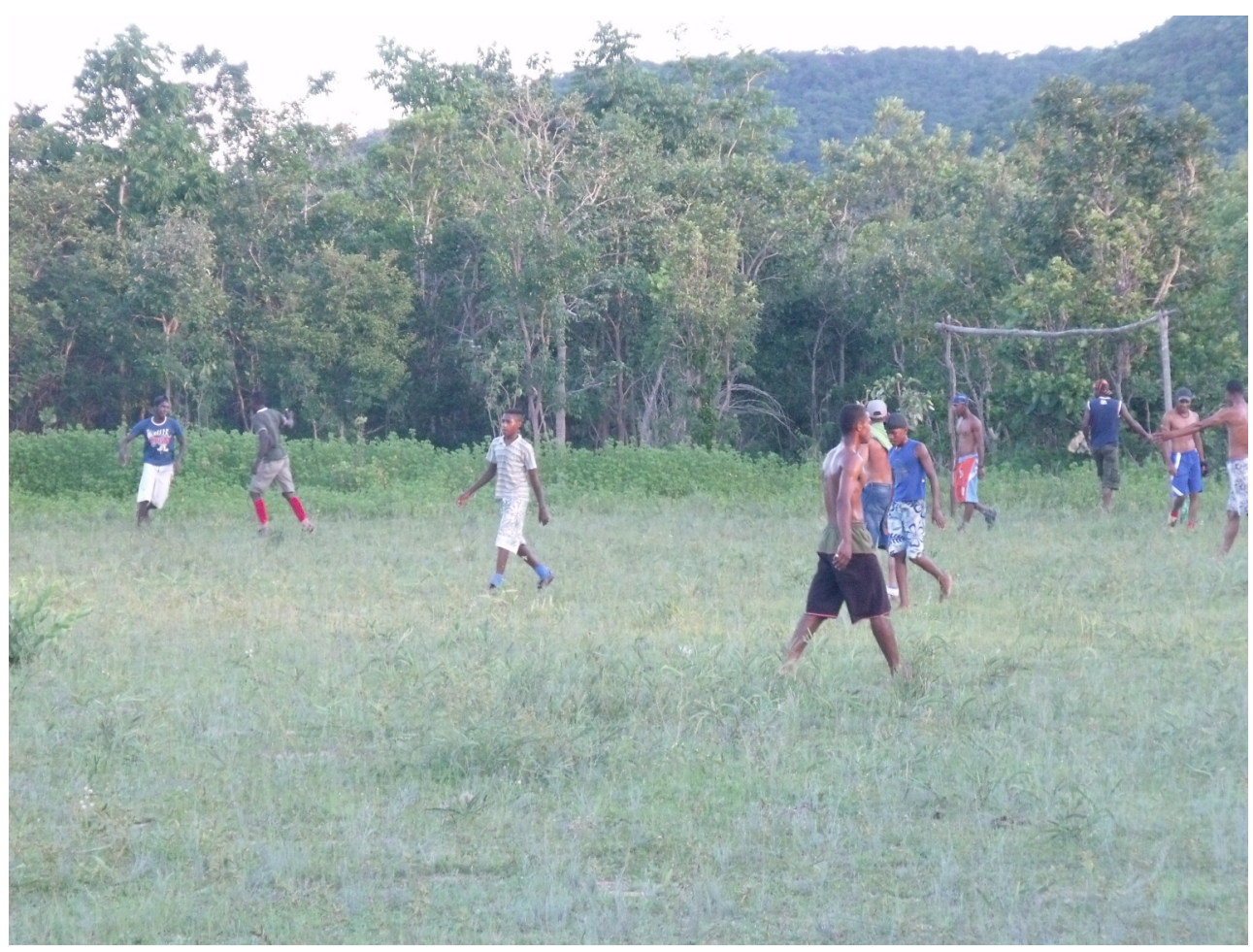

Figura 2: Futebol nos Magalhães (Fonte: Arquivo Labphysis/UFG)

Nessa comunidade, como em outras, só é possível realizar um jogo de futebol em dias de festa ${ }^{5}$, dado que grande parte dos jovens e todas as crianças ficam a maior parte do tempo nas cidades, trabalhando ou estudando, e só regressam à comunidade nos fins de semana, no caso das últimas e, apenas nesses eventos, no caso dos jovens trabalhadores.

Essa festa tem como centralidade uma reza frente a um altar com a imagem do santo, flores e velas, atividade seguida por um jantar oferecido pelos donos da casa a todos os presentes. Logo depois têm início a música e a dança. $\mathrm{O}$ forró é o preferido nessa festividade popular do sertão com os casais dançando até o alvorecer, seguido de um café da manhã, também oferecido pelos donos da casa para cerca de duzentas pessoas que costumam aparecer nas festividades por ali realizadas. O forró, agora frequentemente com som eletrônico, faz com que os

5-Apesar disso, na comunidade do Cedro encontrou-se uma forte presença do futebol, tanto da prática como da assistência aos jogos ao vivo ou pela televisão, especialmente entre os homens, registrada já há algumas décadas. Havia, inclusive, um time de futebol que participava de torneios municipais (DIAS, 2011, In: SILVA; FALCÃO, 2011).

Pensar a Prática, Goiânia, v. 15, n. 1, p. 1-271, jan./mar. 2012 
mais velhos reclamem da "zuera" desse tipo de som, com saudade da sanfona e do violão, dos tempos que ainda tinham a "proeza da dança" (A. M. 81 anos, feminino, entrevista com os mais velhos, Com. Magalhães, 12/10/2009).

Outras três festas compõem o ciclo anual de festividades dessa comunidade, todas em homenagem a santos católicos e realizadas pela matriarca ou seus filhos e genros. Uma delas, a folia mais tradicional no mês de julho; segundo informações, é realizada há mais de 180 anos pelos membros da mesma família, antes mesmo de essa comunidade se estabelecer naquelas paragens, proveniente de outro território quilombola ${ }^{6}$.

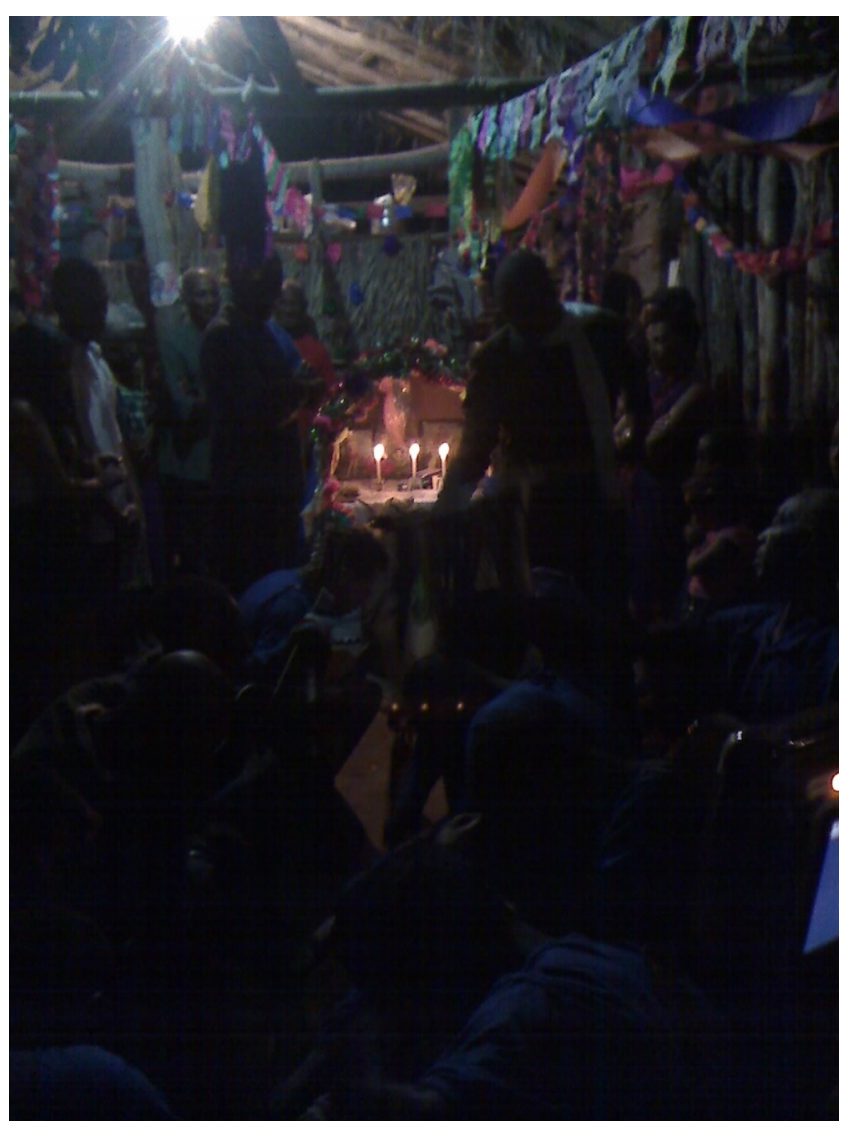

Figura 3: Entrega da Folia aos donos da festa nos Magalhães (Fonte: Arquivo do Labphysis/UFG)

6-Os Magalhães consideram-se kalungueiros, ou seja, identificam-se como parte dos Kalunga, uma das maiores comunidades quilombola do Brasil, que se estende pelo território de três municípios próximos, quais sejam: Teresina de Goiás, Cavalcante e Monte Alegre de Goiás. 
A Folia de Reis de São Sebastião, realizada anualmente entre os dias 9 e 19 de julho, constitui-se como um ritual tradicional com distintos momentos e cada um deles povoado com diferentes técnicas corporais. Os foliões, somente homens, vão "girando a folia" ao visitar a cavalo dezenas de casas dos povoados vizinhos, levando à frente a bandeira de São Sebastião ${ }^{7}$. Como já não há quantidade suficiente de homens na comunidade para girar todo o período da folia, em geral de dez a vinte, é preciso pedir reforço a outras comunidades para manter essa prática tradicional.

Decorridos os dez dias, desde que o encarregado solta a folia e ocorrem vários giros pelas muitas moradias que visitam, é feita a entrega da folia aos donos da festa, casal responsável por ela há alguns anos, em meio a uma grande festa em sua casa. Vários momentos ali ocorrem, com diferentes técnicas e práticas corporais de grande riqueza de detalhes. O ritual com as rezas, o levantamento do mastro, as danças tradicionais, a comida, terminando com o forró noite adentro até o amanhecer.

Dentre as práticas corporais identificadas nas comunidades, talvez, uma das mais peculiares dentre as manifestações quilombola e, especialmente Kalungueira, seja a dança da sussa, da qual não se encontram registros em outras comunidades ${ }^{8}$. Parte da tradição cultural dessa comunidade só é dançada em momentos de festa e em atividades fora da

7-São, basicamente, cinco momentos que constituem esse ritual realizado de maneira mais completa nas casas onde ocorre o "pouso", nas quais dormem os foliões, e parcialmente nas demais que a folia em giro visita. Tais momentos podem ser assim sintetizados: o chamado "agasalho", quando os foliões pedem aos donos da casa para receber o santo; o "canto para o dono da casa", com cânticos em honra a São Benedito, entre outros santos; o chamado "bendito de mesa", quando os foliões agradecem ao santo e ao dono da casa o alimento que acabaram de comer, seguido da dança da sussa, somente aqui de presença mais masculina, eventualmente com a participação dos espectadores; a "curraleira", também considerada outra brincadeira tal como a sussa, com mais liberdade de movimentos e de rimas improvisadas, trazendo situações do cotidiano e desafio entre os foliões; e, por último, a despedi$\mathrm{da}$, onde o dono da casa entrega a bandeira para o "alfere" ir embora com os demais foliões, acompanhada de cantos de despedida (PEDROZA, 2011).

8-Estudos indicam que no Suriname há uma luta, também de origem africana, com esse nome, porém com grafia diferenciada: "susa". Sobre o tema, ver Green (2001, p. 10). 
comunidade quando, então, a sussa aparece como forte marca identitária frente aos demais, especialmente os não quilombolas.

Com o sapateado e a ginga, os giros na roda, os movimentos do quadril, temperados pelas brincadeiras propostas pelas letras das cantigas e lembrando coisas do cotidiano, seja tirando as formigas do corpo ou carregando uma garrafa na cabeça, essa é uma dança em que as mulheres dominam a cena.

Guarda uma carga sertaneja de danças regionais, com influências das tropelias de Goiás e heranças africanas, com características comuns: o pisado, o pandeiro, as palmas, o movimento giratório, o zigue-zague e o confronto de corpos. Assim, tomamos essa manifestação como uma performance afro-sertaneja que funde heranças caipiras, práticas sertanejas e a cultura rústica negra. (SILVA JÚNIOR, 2008, p. 01)

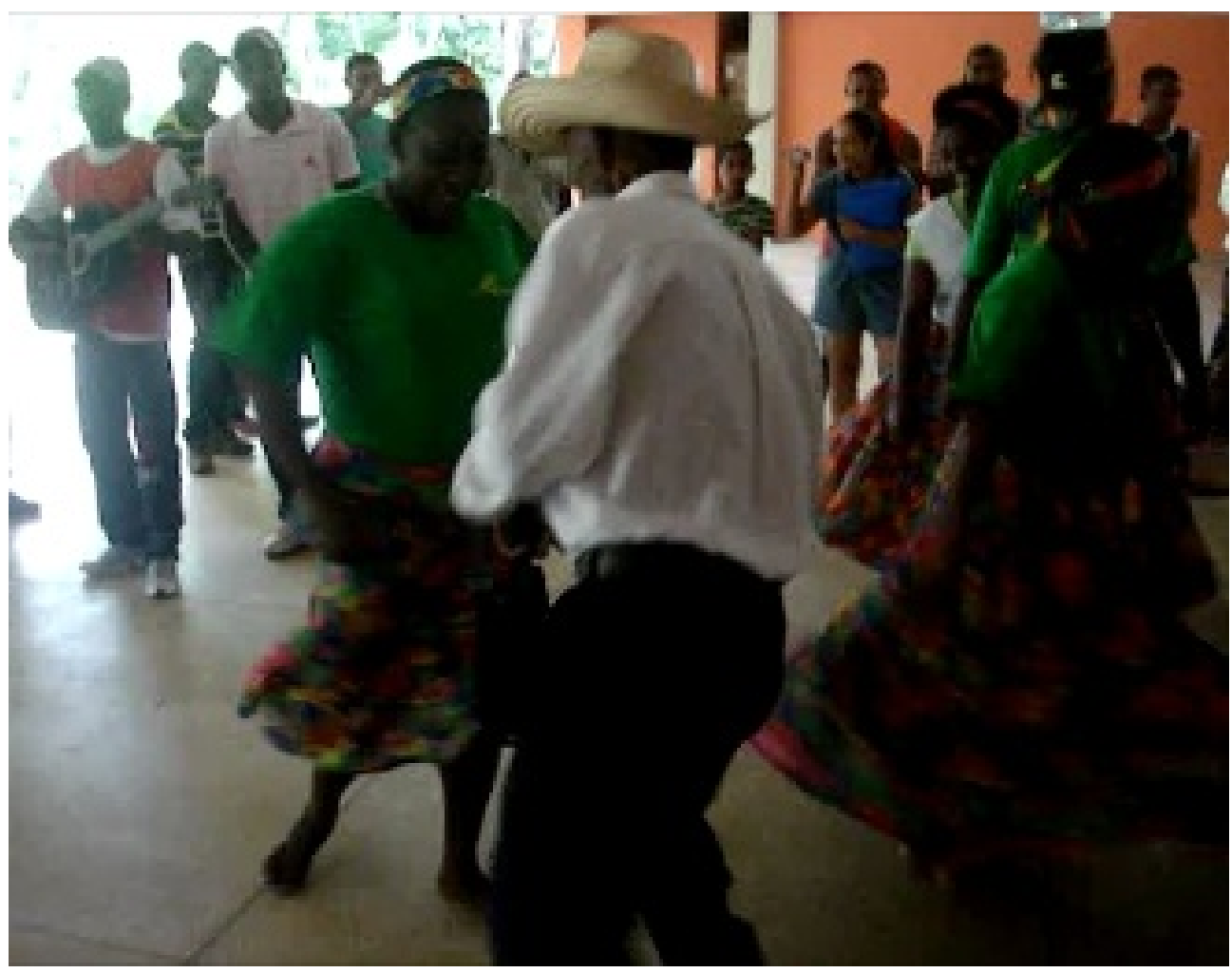

Figura 4: Apresentação da Sussa em evento pelos Kalungas e Magalhães (Fonte: Arquivo Labphysis/UFG).

A catira é outra das danças que compõem o repertório das práticas corporais da comunidade do Cedro, tal como em boa parte das comu- 
nidades populares sertanejas de Goiás. Caracteriza-se como uma dança tradicionalmente masculina de que participam diferentes gerações. Consiste numa combinação de batidas de pés e palmas em uma movimentação que parte de duas fileiras de dançantes, exigindo e prendendo a atenção, pela energia e força de sua apresentação. Um dos membros da comunidade fala da catira como sendo uma dança realizada pelos mais velhos, informando, porém, que atualmente os jovens estão buscando conhecê-la:

Dançavam catira. Aí, eles parece que descrençaram. Aí agora tem os meninos mais novos que estão interessados em resgatar essa cultura da catira, na festa da quadrilha eles apresentaram a catira. (S.P.M., feminino, 31 anos, entrevista com os adultos. Comunidade do Cedro, 19/2/2010)

Tanto nessa como em outras comunidades, no entanto, algumas danças em sua performance são construídas intencionalmente para afirmar a identidade africana, ainda que por meio de outras práticas corporais mais tradicionais. Tradição recriada para, segundo seus próprios interlocutores, "não deixar a tradição cair [...], resgatar o que era da comunidade e perdemos" (G.S.M., masculino, 35 anos, entrevista com os adultos. Comunidade do Cedro, 19/12/2010).

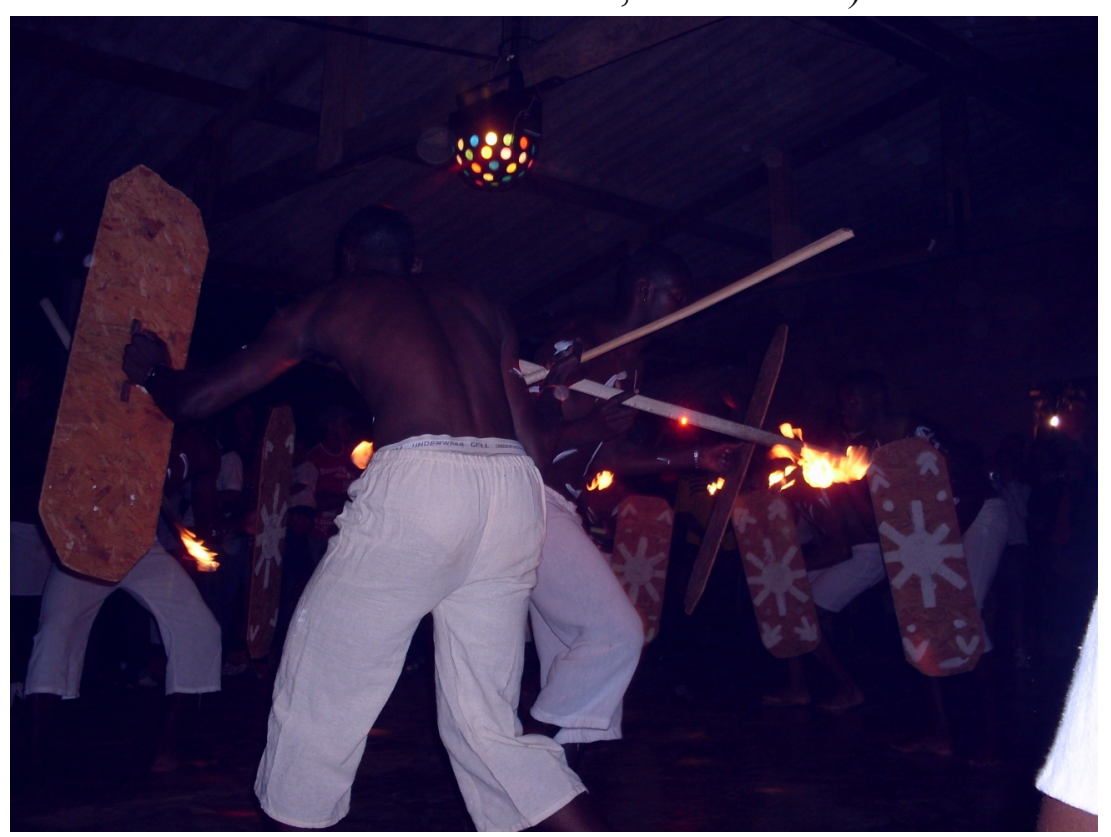

Figura 5: Apresentação do Grupo de Dança do Cedro (Fonte: Arquivo Labphysis/UFG)

Pensar a Prática, Goiânia, v. 15, n. 1, p. 1-271, jan./mar. 2012 
No caso da Comunidade do Cedro, a capoeira constituiu-se como fundamento do trabalho do grupo de dança que se formou, tanto fornecendo um patrimônio rítmico de origem africana, como fornecendo os passos e a preparação corporal para seus praticantes.

A capoeira, em outras comunidades, está no cotidiano das brincadeiras de suas crianças. Como jogo corporal, a capoeira povoa o universo da infância da comunidade Jardim Cascata, mais do que o de jovens e adultos. Tal fato nos faz perguntar se o ensinamento às crianças partiu de alguém mais velho da própria comunidade ou tem origem em grupos externos, tal como nas aulas de Educação Física na escola. De todo modo, é importante dizer que a capoeira passa a ocupar um lugar importante na dinâmica social dessa comunidade, especialmente nos fins de semana e nas festas comunitárias.

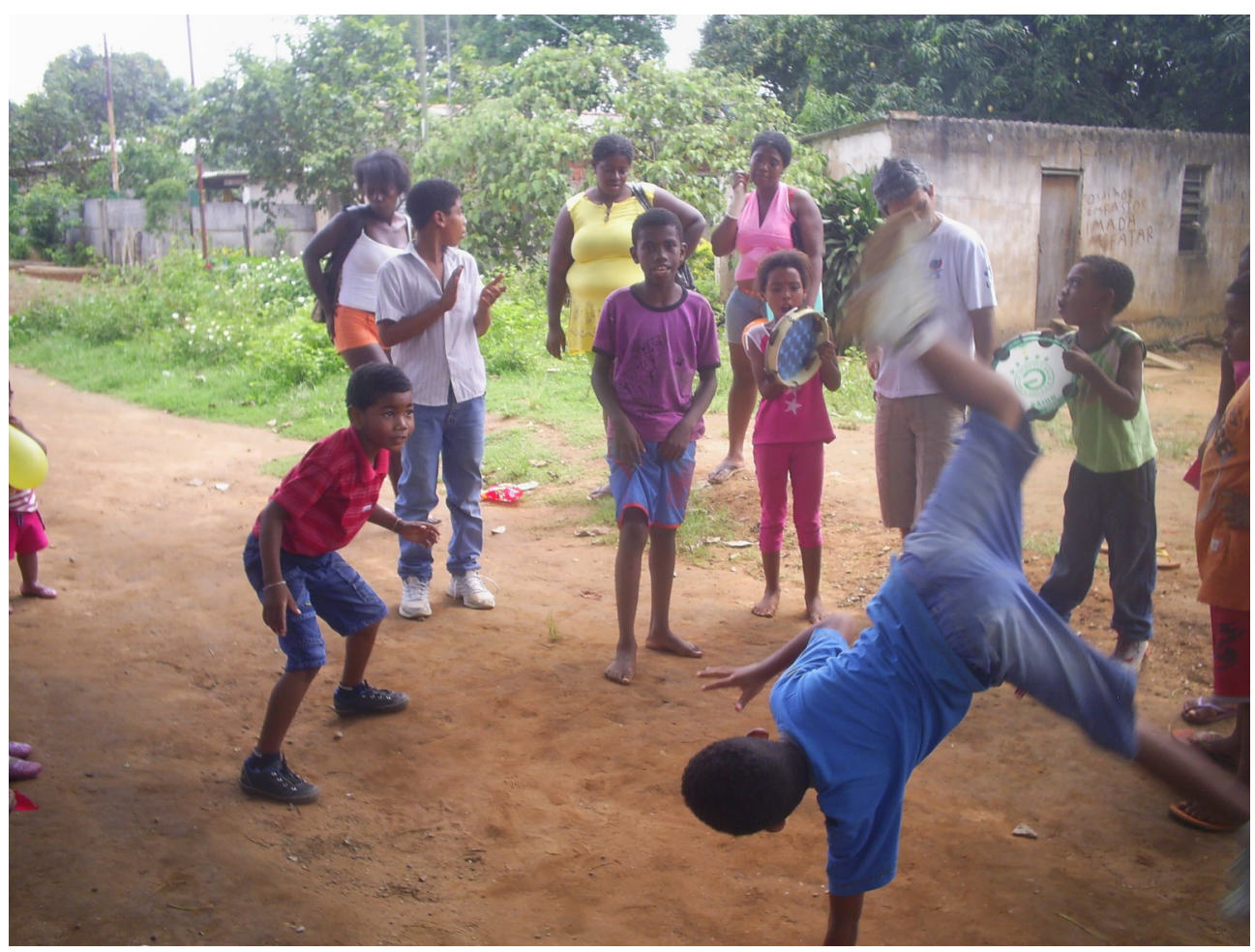

Figura 6: Capoeira na festa do dia das crianças no Jardim Cascata (Fonte: Arquivo Labphysis/UFG).

No que diz respeito aos jogos e brincadeiras da infância, encontram-se também práticas mais tradicionais, assim como muitos outros da contemporaneidade. No relato dos mais velhos sobre sua infância, registram-se informações sobre a grande quantidade de tarefas diárias realizadas em casa e também na roça que são permeadas por jogos e 
brincadeiras. A separação pouco clara entre o tempo do trabalho e do não trabalho, seja na infância ou na idade adulta, faz questionar, inclusive, a existência daquilo que conceituamos como lazer.

Buscando suas memórias, em meio à conversa com sua mulher e filhos, o então patriarca da comunidade Almeida nos contava uma dessas brincadeiras:

Aí nós pegava e cortava uns pau assim, oh, aí nós tocava isso que nem varajão, sabe? Tocando o toco assim, um dum lado e outro do outro. E nós levava o toco lá em riba e voltava lá em cima pra trás e pra baixo assim, oh, e tocava o toco rolando [...] os meninos da minha época tinham que criar para brincar. (J. S. masculino, 71 anos, entrevista com os mais velhos, Comunidade Almeida, 29/20/2009)

É importante observar que, segundo parece, o que sustenta e dá suporte à memória é a coletividade, o grupo de convivência que se mantém vivo, como nos casos dessas comunidades. Essa coletividade é menos visível no meio urbano, onde as pessoas se afastam e acabam não convivendo ou não se visitando mais: "faltam os companheiros que sustentavam as lembranças e que já dispersaram" (BOSI, 2003, p.70).

A infância quilombola está bastante ligada aos jogos e brincadeiras tradicionais que fizeram e fazem parte da infância de uma parcela significativa das pessoas. Essas brincadeiras, a despeito de algumas mudanças, atravessaram gerações e podem ser encontradas até hoje, ainda que com menor frequência, tal como a boneca de pano ou sabugo de milho, o carrinho feito à mão, as brincadeiras de roda, de pular corda, de casinha, a amarelinha, o bodoque ou estilingue, a peteca, a bola de mangaba e de pano, dentre outras.

Ainda que presentes nas comunidades, esses mesmos brinquedos são, em boa parte, industrializados, o que é visto criticamente por uma das lideranças, como decorrência de seu afastamento da comunidade, da desvalorização das brincadeiras tradicionais pela convivência com o meio urbano. É o que aparece nesse depoimento:

Porque essas crianças de hoje, não ficam quase dentro da comunidade, vai na cidade estudar, né [...] não hoje, já estão mais afastados [...] não dá mais valor nisso não. As crianças hoje só 
dão valor mais é ver televisão, é ouvir som, é vídeogame... essas outras coisas mais modernas... (C. H. S. 28 anos, masculino, entrevista com lideranças, Com. Magalhães, 12/10/2009)

A presença dos brinquedos industrializados é forte entre as crianças, assim como o é a televisão em quase todas as casas visitadas. Acrescente-se a esse quadro, o tempo que as crianças passam nas escolas e nas aulas de Educação Física, levando-as a aprender e a gostar de outras atividades, como no caso das brincadeiras e jogos corporais abaixo representadas.

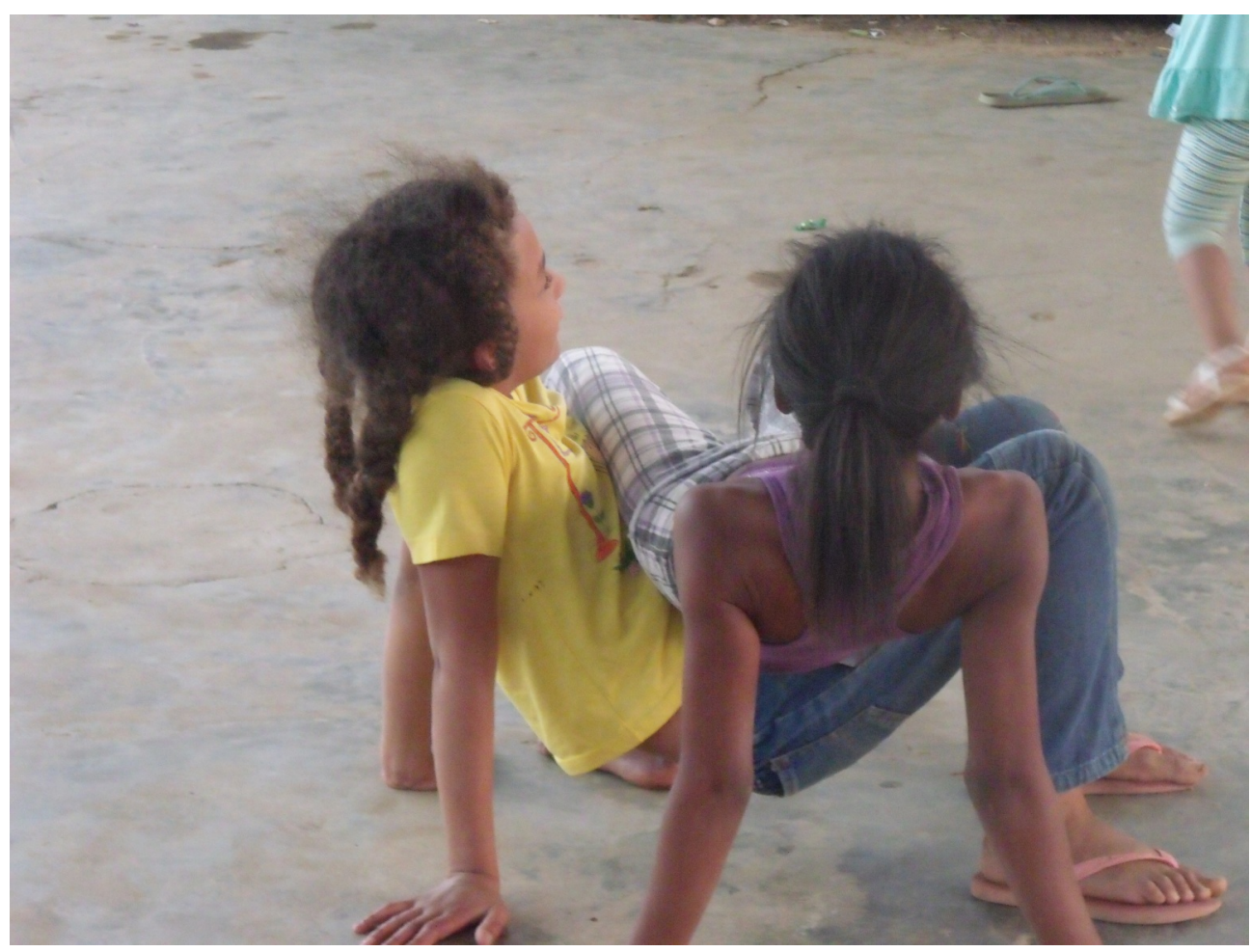

Figura 7: Brincadeiras infantis entre os Almeida (Fonte: Arquivo Labphysis/UFG)

\section{Considerações Finais}

Nas comunidades que pesquisamos, assim como parece ser a realidade das demais relatadas na literatura acadêmica sobre o tema, as festividades constituem momentos fundamentais de encontro e reencontro, de manutenção da unidade e construção permanente de suas identidades. O reforço mútuo aos elementos que os aproximam ocorre, também, nas reuniões associativas em que se organizam e apresentam 
suas demandas aos organismos da política nacional, ainda que em momentos marcados por tensões e disputas internas.

De todo modo, observa-se que as festividades constituem-se em momentos extraordinários, quando ocorre boa parte das práticas corporais que dinamizam a vida social, e se tornam elementos agregadores das comunidades. O forró é, talvez, a prática corporal que mais se faz presente, tanto na atualidade quanto nos relatos desde há décadas, com diferenças dadas principalmente pelo tipo de acompanhamento musical, cada vez menos com os instrumentos tradicionais e mais com equipamentos eletrônicos.

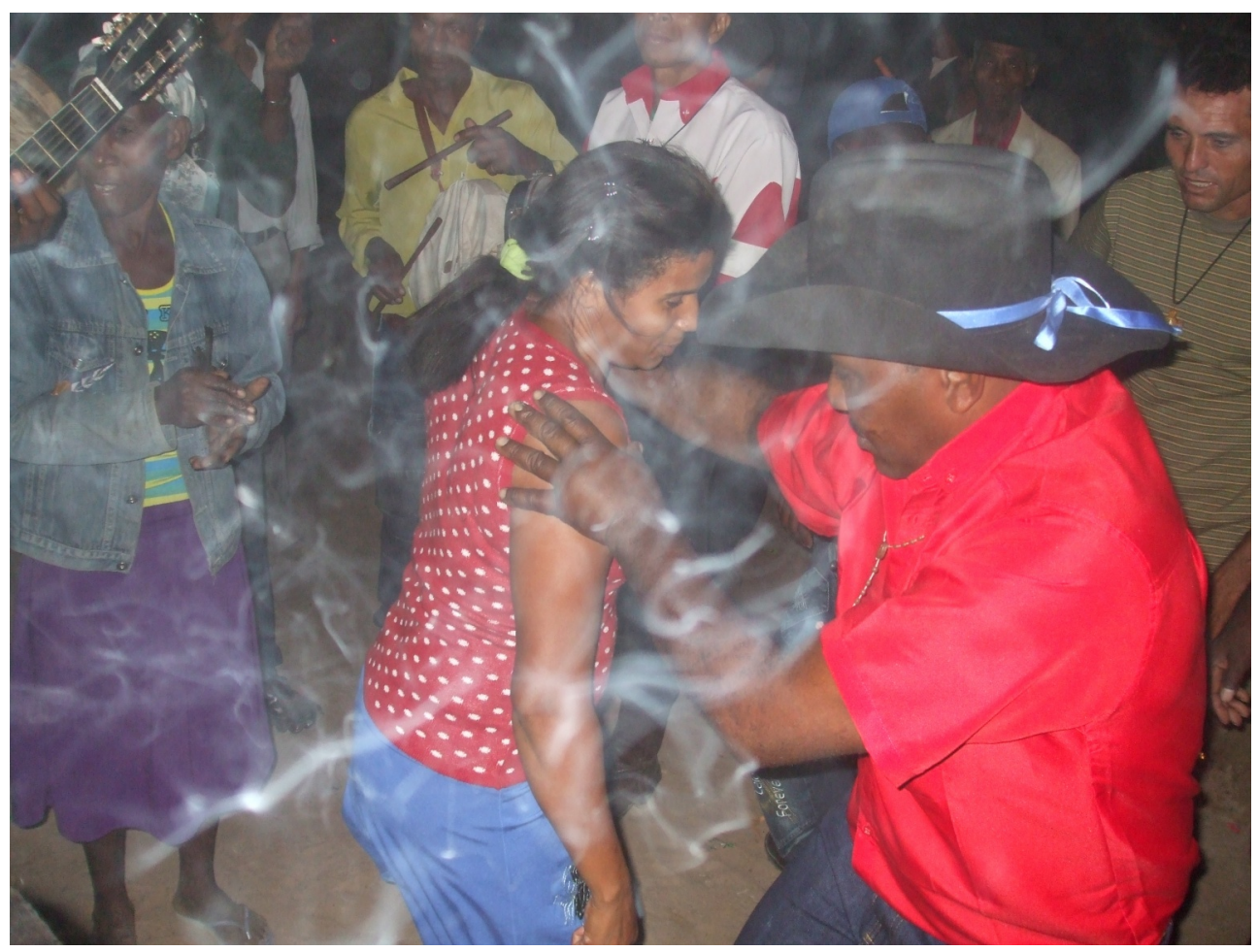

Figura 8: O forró como importante atividade social (Fonte: Arquivo Labphy$\mathrm{sis} / \mathrm{UFG})$.

Outras danças, como a sussa, a catira e a curraleira, também se mostram como práticas corporais importantes e, por vezes, constituem marcas identitárias dessas comunidades. Observamos, também, que somente é possível analisar a gestualidade, os modos e costumes com que as corporalidades e as práticas corporais se expressam, levando em consideração a experiência de ser quilombola, de pertencer a uma comunidade remanescente de quilombo. É por meio dessa experiência, na relação com os demais e com a natureza, portanto, experiência 
étnica, social e historicamente construída, que a identidade quilombola se mostra nos corpos.

Por fim, concluímos que as práticas corporais identificadas nessas comunidades quilombolas estabelecem uma relação com a cultura tradicional que as originaram, mas também com o contexto contemporâneo onde estão imersas, num certo processo de hibridização com a cultura de massas. Quase todas as práticas corporais apresentam, concomitantemente, um conteúdo de generalidade, que se manifesta também em outros contextos sociais que não as comunidades quilombolas, e também marcas de especificidade. Isso porque desempenham um papel de manutenção e reconstrução identitária, com uma forte carga de sentido e significado, por serem postas em movimento por sujeitos que de modo especial, são portadores de trajetória histórica e biográfica única.

Body practices in the marrons experience: a study with communities from the state of Goiás, Brazil

\begin{abstract}
The goal of this work is to analyze the body practices in the marrons experience pointing to some research data obtained from five communities (Almeida, Cedro Kalunga, Magalhães and Jardim Cascata) in the State of Goiás, central Brazil, and also to discuss some of the elements of the historical process and national political agenda on the subject. The "folias", dances like forró, catira and sussa, capoeira, and other games, in addition to soccer, are the more frequently encountered body practices, most of which contain an element of hybridism with mass culture and act as pillars in the rebuilding of tradition while searching for confirming their identities.

Keywords: Body Practices. Traditional Cultures. Quilombolas.

Practicas corporales en la experiencia cimarron: un estudio con comunidades de la província de Goiás, Brasil
\end{abstract}

\title{
Resumen
}

El objetivo de este estudio es analizar el papel desempeñado por las prácticas corporales en la experiencia de los cimarrones indicando algunos datos de investigación desarrollada sobre con cinco comunidades (Almeida, Cedro, Kalunga, Magalhães, y Jardim Cascata) de la Provincia de Goiás, centro de Brasil, señalando también algunos elementos del proceso histórico y de la agenda política sobre el tema. Los festejos, bailes como el forró, la sussa y la catira, capoeira, juegos y juguetes, además del fútbol, son algunas de las prácticas corporales que más se encontraron, casi todos marcados por una hibridez con la cultura de masas y actuando 
como vectores de la reconstrucción de la tradición en búsqueda por reafirmar su identidad.

Palabras clave: Prácticas Corporales. Culturas Tradicionales. Cimarrones.

\section{Referências}

ARRUTI, J. M. Políticas públicas para Quilombos: terra, saúde e educação. In: PAULA, M.; HERINGER, R. (Orgs.). Caminhos convergentes: Estado e sociedade na superação das desigualdades raciais no Brasil. Rio de Janeiro: Fundação Heinrich Boll Stiftung, Actionaid, 2009.

BOSI, E. O tempo vivo da memória: ensaios de psicologia social. São Paulo: Ateliê, 2003.

BRASIL. Decreto n. ${ }^{\mathbf{0}}$ 4.887, de 20 de novembro de 2003. Disponível em <http://www.planalto.gov.br/ccivil_03/Decreto/2003/D4887.htm>. Acesso em: 29/9/2010.

BRANCHER, A. \& AREND, S. M. F. História de Santa Catarina no século XIX. Florianópolis: Ed. da UFSC, 2001.

DOS ANJOS, R. S. A. Territórios das comunidades remanescentes de antigos quilombos no Brasil - primeira configuração espacial. 3. ed. Brasília: Mapas Editora e Consultoria, 2005.

DIAS C. Esporte e lazer em culturas tradicionais. In: SILVA, A. M.; FALCÃO, J. L. C. Práticas corporais em comunidades quilombola de Goiás. Goiânia, Editora PUC/GO, 2011.

GREEN, T. A. Martial Arts of the World: An Encyclopedia. New York: ABC-CLIO, 2001.

KARASCH, M. Quilombos do ouro na Capitania de Goiás. In: REIS, J. J.; GOMES, F. S. (Orgs.). Liberdade por um fio: história dos quilombos no Brasil. São Paulo: Companhia das Letras, 1996.

MAUSS, M. Técnicas corporais. São Paulo: EPU, 1974.

MEYER, D. E. Identidades traduzidas: cultura e docência teuto-brasileiro-evangélica no Rio Grande do Sul. 1. ed. Santa Cruz do Sul: Edunisc, 2000. 
PEDROZA, R. S. Aspectos simbólicos da cultura corporal em rituais populares: performances corporais na Folia de São Sebastião da Comunidade Quilombola Magalhães. In: Anais do II Seminário de Pesquisa da Faculdade de Ciências Sociais da UFG. 2011. p. 34-44.

SILVA, A. M.; PERINI, C. G.; AGOSTINI, M. P. História de bugres e tigres: corpo e natureza em terras catarinenses. Pro-Posições, Campinas, vol. 14, n. 2, 2003, p. 121-146.

SILVA, A. M.; FALCÃO, J. L. C. Práticas corporais em comunidades quilombola de Goiás. Goiânia, Editora PUC/GO, 2011.

SILVA, M. J. Quilombos do Brasil Central: violência e resistência escrava. Goiânia: Kelps, 2008.

SILVA JÚNIOR, A. R. Vozes e versos na festa quilombola dos Kalunga. Revista África e Africanidades, v. ano I, p. 11, 2008a.

SILVA JÚNIOR, A. R. Dança kalunga: a suça, o batuque, o redemunho. Anais do V Congresso da Associação Brasileira de Pesquisa e Pós-Graduação em Artes Cênicas, Belo Horizonte, 2008b. http://www.portalabrace.org/vcongresso/textosestudosperformance.html. Acesso em 21/12/2011.

THOMPSON, E. P. A miséria da teoria. Rio de Janeiro: Zahar, 1981.

Recebido em: 23/10/2011

Revisado em: 15/12/2011

Aprovado em: 24/02/2012

Endereço para correspondência

anamarcia@pq.cnpq.br

Ana Márcia Silva

Universidade Federal de Goiás

Faculdade de Educação Física

Campus Samambaia

Caixa Postal 131

CEP: 74001-970 Goiânia - Goiás - Brasil 